\title{
Caracterização microestrutural da argila expandida para aplicação como agregado em concreto estrutural leve
}

\section{(Microstructural evaluation of expanded clay to be used as lightweight aggregate in structural concrete)}

\author{
W. G. Moravia, C. A. S. Oliveira, A. G. Gumieri, W. L. Vasconcelos. \\ Departamento de Engenharia Metalúrgica, Universidade Federal de Minas Gerais, R. Espírito Santo 35 \\ Belo Horizonte, MG 30160-030 \\ webermoravia@oi.com.br
}

\begin{abstract}
Resumo
A utilização da argila expandida como agregado graúdo é economicamente viável na fabricação de concretos devido à redução da massa especifica que estes agregados proporcionam, minimizando os carregamentos atuantes nas estruturas. O objetivo deste trabalho é caracterizar a microestrutura do agregado leve de argila expandida visando sua utilização na fabricação de concretos. Na caracterização física da argila expandida foram avaliadas a massa unitária, a granulometria e a absorção de água por imersão total do agregado. Na caracterização microestrutural, foram realizadas análise química, microscopia eletrônica de varredura, difração de raios X e porosimetria por intrusão de mercúrio. A argila expandida apresentou granulometria entre as britas com graduação 0 e 1, e apresentou alta absorção de água devido à elevada porosidade deste agregado. Na análise de difração de raios $\mathrm{X}$ evidenciou-se a presença de sílica na forma mineral de $\alpha$-quartzo, silicato de magnésio e óxido de alumínio e magnésio.
\end{abstract}

Palavras-chave: argila expandida, concreto leve, microestrutura.

\begin{abstract}
The use of expanded clay as aggregate is economically feasible in the manufacturing of concrete due to the decrease in bulk density, provided by these aggregates, minimizing the total weight of the structures. The objective of this work is to characterize the microstructure of expanded clay aggregates which are used in the manufacturing of lightweight concretes. The expanded clay was evaluated concerning of the density, the granulometry and water absorption after total immersion of the aggregate. The chemical analysis, scanning electron microscopy, $X$-ray diffraction and mercury intrusion porosimetry were used as well. The expanded clay presented granulometry between the aggregates grades 0 and 1 and high water absorption due to the high porosity of the aggregate. The X-ray diffraction data showed the presence of $\alpha$-quartz, magnesium silicate and magnesium aluminum oxide.
\end{abstract}

Keywords: expanded clay, light weight concrete, microstructure.

\section{INTRODUÇÃO}

A argila expandida é o produto obtido por aquecimento de alguns tipos de argila na temperatura em torno de $1200{ }^{\circ} \mathrm{C}$. Próximo desta temperatura, uma parte dos constituintes do material se funde gerando uma massa viscosa, enquanto a outra parte se decompõe quimicamente liberando gases que são incorporados por esta massa sinterizada, expandindo-a em até sete vezes o seu volume inicial. Esses gases, retidos no interior da argila, não podem escapar para o seu exterior devido à fase líquida que envolve as partículas da argila. Essa estrutura porosa se mantém após o resfriamento, de modo que a massa unitária do material resultante torna-se menor do que antes do aquecimento, podendo ser utilizada como agregado graúdo na fabricação de concretos leves, com o objetivo de reduzir o peso próprio das estruturas [1-3].

O agregado de argila expandida pode ser produzido pelo tratamento térmico da matéria-prima, triturada e classificada granulometricamente, ou moída e pelotizada, feito, geralmente, em forno rotativo a gás ou óleo diesel, similar aos usados na fabricação de cimento Portland. Pode, também, ser obtido por sinterização contínua. Nesse caso, o material bem umedecido é transportado numa esteira, sob queimadores, de modo que o calor atinge gradualmente toda a espessura da camada [45]. Os agregados de argila expandida, produzidos pelo 
processo de sinterização contínua possuem massa específica aparente na faixa compreendida entre $650 \mathrm{~kg} /$ $\mathrm{m}^{3}$ e $900 \mathrm{~kg} / \mathrm{m}^{3}$ e os produzidos em forno rotativo, entre $300 \mathrm{~kg} / \mathrm{m}^{3}$ e $650 \mathrm{~kg} / \mathrm{m}^{3}$ [5].

A granulometria do agregado e o fator água/cimento exercem influência na trabalhabilidade dos concretos e devem ser considerados em conjunto, pois quanto menor for a granulometria do agregado maior será a quantidade de água necessária para envolver os grãos do mesmo, formando uma película d'água responsável por uma boa trabalhabilidade [5].

A caracterização da microestrutura da argila expandida é importante para a fabricação dos concretos, auxiliando na compreensão das reações físico-químicas que ocorrem na sua interface com a matriz de cimento. Devido à sua alta porosidade, a argila expandida proporciona uma redução da resistência mecânica dos concretos [6]. Por outro lado, uma importante característica do agregado leve é a boa aderência entre este e a pasta hidratada de cimento que o envolve. Esta aderência ocorre pela textura áspera da superfície do agregado leve, resultando em um intertravamento mecânico entre o agregado e a pasta [7]. A aderência também pode ser melhorada pela água absorvida pelo agregado no momento da mistura do concreto, que com o tempo, torna-se disponível para a hidratação do cimento anidro [8-9]. Parte dessa hidratação ocorre na região da interface agregadomatriz, tornando a aderência entre o agregado e a matriz mais resistente [5].

A argila expandida analisada foi fornecida por uma empresa do estado de S. Paulo e está disponível comercialmente no mercado brasileiro. Sua matériaprima foi retirada do recôncavo baiano e processada em forno rotativo. Para que a argila tenha características expansivas, a composição química da matéria-prima deve estar dentro das zonas apresentadas na Fig. 1 [2].

No Brasil, a produção de argila expandida se restringe a um único fabricante, sendo sua produção voltada, principalmente, para a indústria têxtil (estonagem de ”jeans”) e de ornamentação (decoração de jardins).

O conhecimento das características físicas, químicas e mineralógicas da argila expandida são importantes para a indústria da construção civil.

Este trabalho tem por objetivo caracterizar a argila expandida disponível no mercado, visando sua melhor especificação e utilização para produção de concretos leves, já que existem poucos dados na literatura sobre este material.

\section{MATERIAIS E MÉTODOS}

Na caracterização física da argila expandida avaliouse a granulometria, a massa unitária, a massa específica real e a absorção de água do agregado. O ensaio de granulometria foi realizado conforme a NBR 7217 Agregados - determinação da composição granulométrica [10].

A massa unitária foi determinada segundo as prescrições da NBR 7251 - Agregado em estado solto - determinação da massa unitária [11].

A massa específica real foi obtida por picnometria com hélio. Para a realização deste ensaio, o material foi moído com a finalidade de expor os poros fechados (isolados), de forma que o volume medido correspondesse somente ao volume do sólido, excluindo-se os poros da amostra.
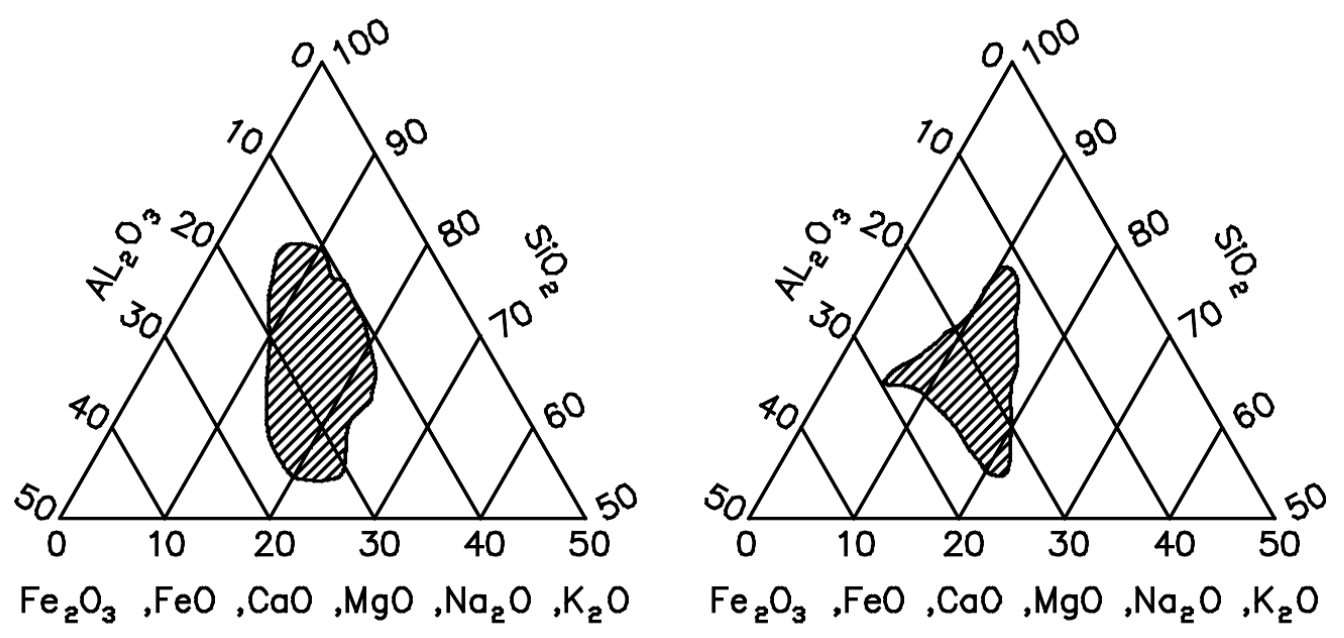

Figura 1: Zonas em que se encontram as composições químicas das argilas com característica expansiva [2]. [Figure 1: Chemical compositions zones of clays with expansive characteristics [2].] 
Tabela I - Técnicas de análise química da argila expandida. [Table I - Chemical analysis technics of expanded clay.]

\begin{tabular}{|c|c|}
\hline Elementos & Metodologia \\
\hline Ca, Mg & $\begin{array}{c}\text { Volumetria, por } \\
\text { complexão, com EDTA. }\end{array}$ \\
\hline Si & $\begin{array}{l}\text { Gravimetria, solubilização } \\
\text { com } \mathrm{HCl} \text {, fluorização com HF. }\end{array}$ \\
\hline $\mathrm{Al}, \mathrm{Na}, \mathrm{K}$ & $\begin{array}{c}\text { Espectrofotometria de absorção } \\
\text { atômica equipamento } \\
\text { Analyst 300, Perkin-Elmer, } \\
\text { modo chama. }\end{array}$ \\
\hline $\mathrm{Fe}$ & $\begin{array}{l}\text { Volumetria, por óxi-redução, } \\
\text { com dicromato de potássio. }\end{array}$ \\
\hline $\mathrm{C}$ & $\begin{array}{l}\text { Combustão direta, com detecção por } \\
\text { infravermelho equipamento } \\
\text { CS-244, LECO. }\end{array}$ \\
\hline PPC & $\begin{array}{l}\text { Calcinação a } 1000{ }^{\circ} \mathrm{C} \text {, } \\
\text { até peso constante. }\end{array}$ \\
\hline
\end{tabular}

O teor de absorção foi obtido pelo método da norma NBR 9776 - Agregado - determinação da absorção e massa específica do agregado graúdo. A evolução da absorção do agregado foi avaliada para diversos intervalos de tempo [12].

Para caracterização da microestrutura da argila expandida foram realizadas análises química, mineralógica, morfológica e avaliação da porosidade.

Na caracterização química empregou-se a metodologia descrita na Tabela I.

$\mathrm{Na}$ caracterização mineralógica, as principais fases cristalinas na amostra de argila expandida foram determinadas utilizando-se a técnica de difração de raios $X$ (DRX). Foi empregado um difratômetro PHILIPS modelo PW-3710 (radiação Cuk $\alpha$, corrente $30 \mathrm{~mA}$ e tensão $40 \mathrm{kV}$, varredura com passo de 0,060 e tempo de coleta de 1,0 s/passo). Para a análise das fases cristalinas, os valores de "d" (distância interplanar) foram adotados com aproximação de $\pm 0,01 \AA$ [13].

A análise morfológica e a análise química elementar das fases presentes na argila expandida foram obtidas pela técnica de microscopia eletrônica de varredura (MEV) com analisador de raios $\mathrm{X}$ por dispersão de energia (EDS). Foi empregado um microscópio marca PHILIPS, modelo JSM-80. Alguns grãos da amostra analisada apresentavam a superfície interna exposta, provavelmente, devido ao processo de produção ou ao transporte. As fotomicrografias foram obtidas por elétrons secundários, da superfície interna exposta e da superfície externa dos grãos, sendo as amostras metalizadas com filme de carbono.

A porosidade aparente da amostra foi determinada utilizando porosimetria por intrusão de mercúrio. Esta técnica é adequada para avaliar poros com diâmetros entre $0,04 \mu \mathrm{m}$ e $300 \mu \mathrm{m}$. A análise foi realizada considerando-se o volume dos grãos da amostra na forma de agregados. Foram escolhidos agregados com dimensão de 9,5 mm por esta dimensão representar grande parte da granulometria da argila expandida estudada neste trabalho.

A resistência de agregados convencionais como a brita calcária, é obtida através da extração de testemunhos da rocha e ruptura à compressão destes corpos-de-prova de acordo com as normas. Devido à grande dificuldade de se obter testemunhos de argila expandida, já que este material é produzido industrialmente, e à falta de um método confiável para avaliação da resistência desse agregado, optou-se por uma avaliação qualitativa, a partir da comparação entre as resistências à compressão do concreto com brita calcária e do concreto produzido com agregado de argila expandida.

Para a avaliação do desempenho mecânico dos concretos foram adotados três diferentes traços (pobre, médio e rico em consumo de cimento) para o concreto convencional (referência) e para o concreto leve (utilizando argila expandida como agregado graúdo).

Os ensaios de resistência à compressão axial foram conduzidos de acordo com a NBR 5739 - Ensaios de compressão de corpos de prova cilíndricos de concreto [14]. Foram rompidos corpos de prova com $10 \mathrm{~cm}$ de diâmetro e $20 \mathrm{~cm}$ de altura, nas idades 3, 7 e 28 dias, utilizando-se uma prensa hidráulica.

\section{RESULTADOS E DISCUSSÃO}

A Tabela II apresenta os resultados do ensaio de granulometria do agregado de argila expandida.

Tabela II - Análise granulométrica da argila expandida. [Table II - Granulometric analysis of the expanded clay.]

\begin{tabular}{cccc}
\hline $\begin{array}{c}\text { Peneiras } \\
(\mathrm{mm})\end{array}$ & $\begin{array}{c}\text { Material } \\
\text { Retido (gramas) }\end{array}$ & \% Retida & $\begin{array}{c}\text { \% Retida } \\
\text { Acumulada }\end{array}$ \\
\hline 19 & 0 & 0 & 0 \\
12,5 & 433 & 9 & 9 \\
9,5 & 2553 & 51 & 60 \\
6,3 & 1520 & 30 & 90 \\
4,8 & 393 & 8 & 98 \\
Fundo & 100 & 2 & 100 \\
\hline Total & 5000 & 100 & \\
\hline Dimensão & $19 \mathrm{~mm}$ & - & - \\
Máxima & & & \\
Característica & & & \\
\hline Módulo de & & & - \\
Finura & 6,48 & - & \\
\hline
\end{tabular}


Com base na análise granulométrica da argila expandida, Tabela II, conclui-se que a argila expandida possui dimensão máxima característica de $19 \mathrm{~mm}$. Não é possível classificar granulometricamente este agregado graúdo de acordo com as especificações da Norma NBR 7211 (Agregados para concreto) [15], pois as porcentagens retidas acumuladas por peneira não são compatíveis com os limites granulométricos prescritos nesta norma. Para um traço de concreto utilizando argila expandida, recomenda-se que seja feita uma composição granulométrica deste agregado, para que a mesma corresponda à granulometria do agregado convencional.

Na Tabela III estão apresentados os resultados da massa unitária, massa específica real e da absorção da argila expandida utilizada neste trabalho.

A massa unitária se encontra na faixa entre $300 \mathrm{~kg} /$ $\mathrm{m}^{3}$ e $650 \mathrm{~kg} / \mathrm{m}^{3}$, correspondente às argilas expandidas produzidas em forno rotativo.

Tabela III - Massa unitária, massa específica real e absorção da argila expandida.

[Table III - Bulk density, absolute specific gravity and absorption of the expanded clay.]

\begin{tabular}{|c|c|c|}
\hline Ensaios & \multicolumn{2}{|c|}{ Argila Expandida } \\
\hline Massa unitária (kg/dm³) & \multicolumn{2}{|r|}{0,46} \\
\hline Massa específica real $\left(\mathrm{g} / \mathrm{cm}^{3}\right)$ & \multicolumn{2}{|r|}{2,57} \\
\hline Absorção de Água & \multicolumn{2}{|r|}{ Tempo (min) } \\
\hline \multirow[t]{2}{*}{ por Imersão Total (\%) } & 5 & $1530 \quad 6024 \mathrm{~h}$ \\
\hline & 15 & $\begin{array}{llll}15 & 20 & 25 & 30\end{array}$ \\
\hline
\end{tabular}

A massa específica real encontrada aproxima-se dos valores da massa específica real da matéria-prima, pois quando moída, a matriz porosa da argila expandida não mais existirá. Assim, quanto maior o agregado de argila expandida, maior será a porosidade intrínseca do material, e menor será a massa unitária.

De acordo com os resultados apresentados na Tabela III, verifica-se que a argila expandida apresenta alta absorção de água em relação a agregados convencionais. Esta elevada absorção de água está relacionada à estrutura porosa dos seus grãos. Verificou-se que durante o intervalo de 24 horas, sugerido pela norma NBR 9776, a absorção de água não se estabilizou.

Na Tabela IV estão apresentados os resultados do ensaio de porosimetria por intrusão de mercúrio.

Os dados da Tabela IV mostram que a argila expandida apresenta uma alta porosidade aparente, fato este que corrobora a alta absorção do agregado.

Na Tabela V estão apresentados os resultados obtidos na análise química da argila expandida, apresentados na forma de seus respectivos óxidos. Os teores dos
Tabela IV - Resultados obtidos no ensaio de porosimetria por intrusão de mercúrio.

[Table IV - Results of the mercury intrusion porosimetry.]

\begin{tabular}{|c|c|c|c|c|}
\hline $\begin{array}{c}\text { Massa } \\
\text { Amostra } \\
\text { (g) }\end{array}$ & $\begin{array}{c}\text { Volume } \\
\text { Total } \\
\text { Mercúrio } \\
\text { Introduzido } \\
\text { (mL/g) }\end{array}$ & $\begin{array}{c}\text { Área } \\
\text { Total } \\
\text { dos } \\
\text { Poros } \\
\left(\mathrm{m}^{2} / \mathrm{g}\right)\end{array}$ & $\begin{array}{l}\text { Diâmetro } \\
\text { Médio dos } \\
\text { Poros } \\
(\mu \mathrm{m})\end{array}$ & $\begin{array}{l}\text { Porosidade } \\
\text { Aparente }\end{array}$ \\
\hline 1,4781 & 0,1728 & 3,1 & 0,22 & 19 \\
\hline
\end{tabular}

Tabela V - Análise química da argila expandida. [Table V-Chemical analysis of expanded clay.]

\begin{tabular}{ccc}
\hline Óxido & $\%$ & Limites Químicos (\%) \\
\hline $\mathrm{SiO}_{2}$ & 63,4 & 50 a 65 \\
$\mathrm{Fe}_{2} \mathrm{O}_{3}$ & 11,7 & 5 a 9 \\
$\mathrm{Al}_{2} \mathrm{O}_{3}$ & 10,5 & 16 a 20 \\
$\mathrm{~K}_{2} \mathrm{O}$ & 4,3 & \\
$\mathrm{Na}_{2} \mathrm{O}$ & 0,39 & \\
$\mathrm{MgO}$ & 3,7 & 1,5 a 3,5 \\
$\mathrm{TiO}_{2}$ & 0,42 & - \\
$\mathrm{CaO}$ & 0,25 & 1 a 4 \\
\hline $\mathrm{S}$ & 0,02 & 0 a 1,5 \\
$\mathrm{PPC}$ & 0,81 & 6 a 8 \\
\hline
\end{tabular}

constituintes (limites químicos) para que a argila tenha características expansivas [2] também estão listados nesta tabela. Esses limites não devem ser ultrapassados, pois a argila não se fundiria a uma temperatura suficientemente baixa, ou fundiria numa massa insuficientemente viscosa [2].

Pelos resultados da Tabela V pode-se observar que no geral a composição química da amostra encontrase dentro da faixa considerada para argilas com características expansivas.

Na Fig. 2 estão apresentados o difratograma e as principais fases químicas da argila expandida tais como: sílica $\left(\mathrm{SiO}_{2}\right)$ na forma morfológica de $\alpha$-quartzo; silicato de magnésio $\left(\mathrm{Mg}\left(\mathrm{SiO}_{4}\right)\right.$ e óxido de alumínio e magnésio $\left(\mathrm{MgAl}_{2} \mathrm{O}_{4}\right)$ na forma de espinélio.

Observa-se no difratograma uma elevação da linha de base entre, aproximadamente, $15^{\circ}$ e $40^{\circ}$ indicando a presença de fases amorfas na argila expandida estudada.

Na Fig. 3 estão apresentadas micrografias obtidas por MEV, ilustrando a morfologia da argila expandida.

Verifica-se que a superfície externa da argila expandida apresenta textura mais lisa (Figs. 3a e 3c) que a superfície interna da amostra (Figs. 3b e 3d). Visualiza- 
Tabela VI - Composição química elementar média das áreas analisadas EDS.

[Table VI - Average chemical composition in the analyzed areas EDS.]

\begin{tabular}{ccc}
\hline Óxido & $\begin{array}{c}\text { Superfície } \\
\text { interna(\%) }\end{array}$ & $\begin{array}{c}\text { Superfície } \\
\text { externa(\%) }\end{array}$ \\
\hline $\mathrm{O}$ & 45,4 & 46,9 \\
$\mathrm{Si}$ & 24,8 & 26,4 \\
$\mathrm{Fe}$ & 9,4 & 5,6 \\
$\mathrm{Al}$ & 10,4 & 12,4 \\
$\mathrm{~K}$ & 5,1 & 4,1 \\
$\mathrm{Na}$ & 0,6 & 0,5 \\
$\mathrm{Mg}$ & 2,4 & 1,8 \\
$\mathrm{Ti}$ & 0,8 & 0,8 \\
$\mathrm{Ca}$ & 1,0 & 1,6 \\
\hline
\end{tabular}
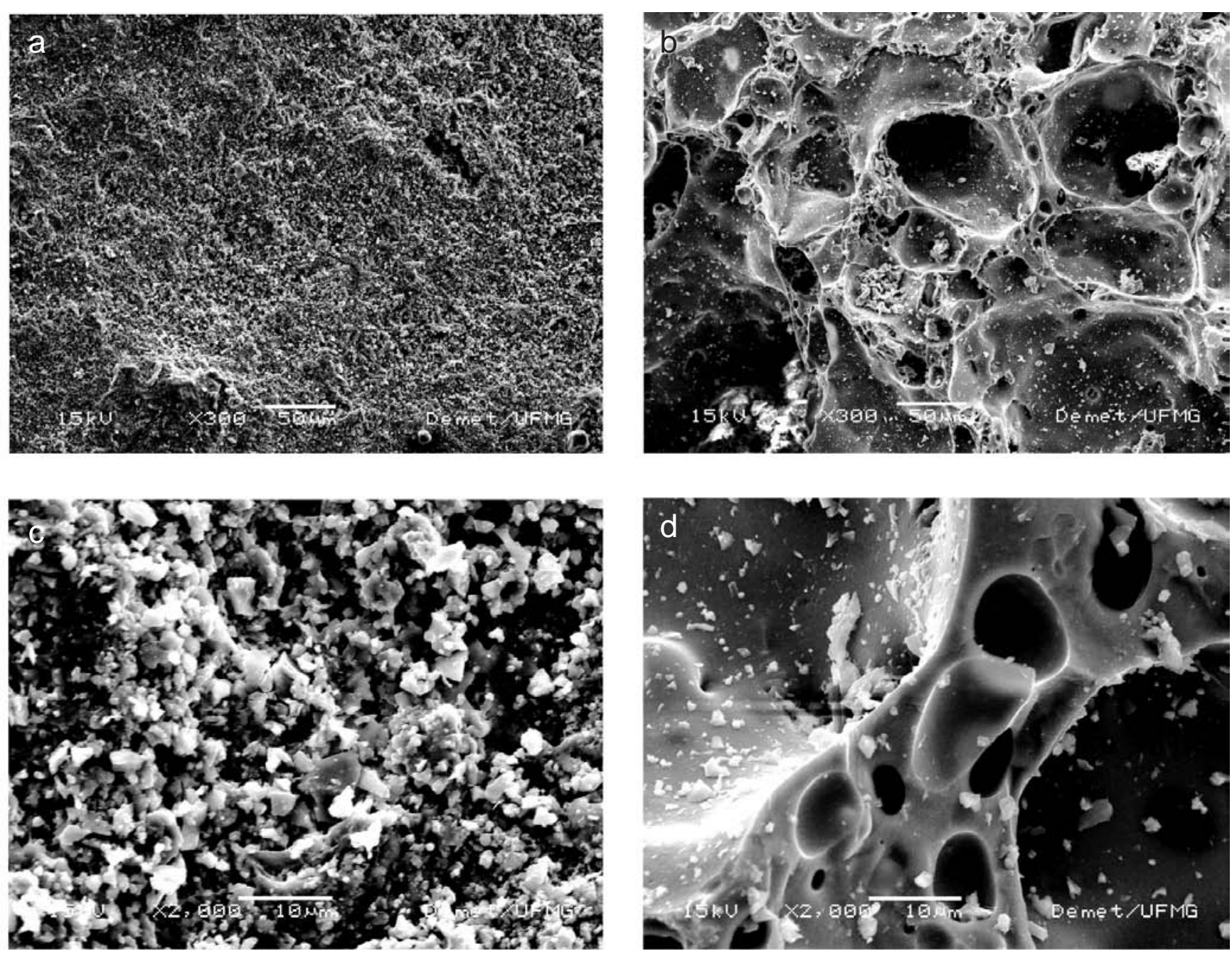

Figura 3: Imagens por MEV da argila expandida: (a) superfície externa (300X); (b) superfície interna (300X); (c) superfície externa (1200X); (d) superfície interna (1200X).

[Figure 3: SEM pictures of expanded clay (a) external surface (300X); (b) internal surface (300X); (c) external surface (1200X); (d) internal surface $(1200 X)$.] 
se que a superfície interna apresenta maior quantidade de poros, não ocorrendo a interconectividade dos mesmos. A maior porosidade da superfície interna está relacionada ao surgimento de bolhas de gases originados no processo de fabricação da argila expandida.

A Tabela VI apresenta a composição química elementar geral, nas áreas das Figs. 3a e 3c, obtidas por EDS.

Verifica-se, no geral, que a argila expandida apresenta grande incidência dos elementos $\mathrm{O}, \mathrm{Si}, \mathrm{Al}$ e $\mathrm{Fe}$. O alto teor do oxigênio pode ser explicado pela sua presença na estrutura cristalina dos óxidos e silicatos que compõem a amostra.

Na Fig. 4, pode-se observar que, aos 28 dias de idade, o concreto leve apresentou uma redução de $15 \%$ a $24 \%$ da resistência à compressão em relação ao concreto de referência.

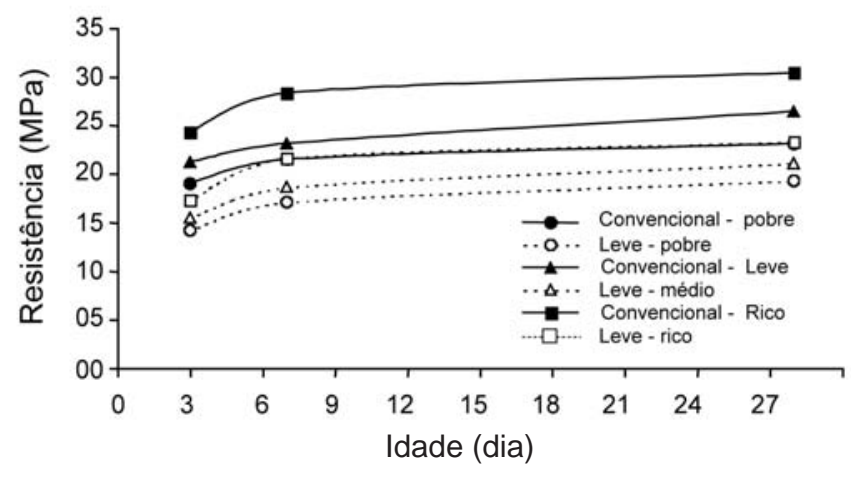

Figura 4: Resistência à compressão dos concretos analisados.

[Figure 4: Compressive strength of concretes.]

\section{CONCLUSÕES}

A argila expandida estudada apresenta dimensão máxima característica igual a $19 \mathrm{~mm}$. A massa unitária se encontra na faixa entre $300 \mathrm{~kg} / \mathrm{m}^{3}$ e $650 \mathrm{~kg} / \mathrm{m}^{3}$, correspondente às argilas expandidas produzidas em forno rotativo.

A argila expandida apresenta alta porosidade em relação aos agregados convencionais, devido à estrutura porosa dos seus grãos, o que também aumenta sua absorção de água. Esta elevada absorção de água, quando não prevista, pode ser prejudicial ao concreto, reduzindo sua trabalhabilidade. Além disso, parte da água necessária para a hidratação dos compostos do cimento será absorvida por este agregado, reduzindo, possivelmente, a resistência mecânica do concreto. Como solução, recomenda-se a saturação do agregado, uma pré-umidificação ou a correção do teor de água utilizada na dosagem do traço de concreto.

A argila expandida apresenta, basicamente, os elementos químicos silício, alumínio e ferro, em sua composição química. Na análise por DRX, o difratograma da amostra apresenta um halo de amorfismo, sugerindo a presença de fases amorfas, formadas durante o processo de fabricação da argila expandida.

Verificou-se que todos os traços do concreto leve, apresentaram queda de resistência em relação aos respectivos traços do concreto de referência. Podemos concluir que a argila expandida possui menor resistência à compressão em relação à brita calcária.

\section{AGRADECIMENTOS}

À empresa CINEXPAM, pelo fornecimento da amostra de argila expandida necessária para realização deste trabalho. Ao CNPq e à CAPES, pelo apoio financeiro para o desenvolvimento deste trabalho.

\section{REFERÊNCIAS}

[1] A. Short, W. Kinniburgh, Lightweight Concrete, $1^{\text {st }}$ Edition, C.R. Books Limited, London, England (1963) $511 \mathrm{p}$.

[2] A. S. Coutinho, Fabrico e Propriedades do Betão. $2^{\mathrm{a}}$.ed., Vol 1, LNEC, Lisboa, Portugal (1988) 400 p.

[3] P. S. Santos, Ciência e Tecnologia de Argilas. 2ªd., Vol 1 e 2, Editora Edgard Blücher, S. Paulo, Brasil (1992).

[4] A. M. Neville, Propriedades do Concreto, Editora PINI, S. Paulo, Brasil (1997) 828 p.

[5] P. K Mehta, P. J. M. Monteiro, Concreto - Estrutura, Propriedades e Materiais, $1^{\text {a }}$. ed., Editora PINI, S. Paulo, Brasil (1994) 573 p.

[6] R. Wasserman, A. Bentur, Cement \& Concrete Composites 18 (1996) 67-76.

[7] M. H. Zhang, O. E. Gjprv, Cem. and Conc. Res. 22 (1992) 47-55.

[8] S. Weber, H. W. Reinhardt, Advanced Cement Based Materials 6 (1997) 59-68.

[9] M. Gesoglu, T. Özturan, E. Güneyisi, Cem. and Conc. Res. 34 (2004) 1121-1130.

[10] Associação Brasileira de Normas Técnicas, NBR 7217 - Agregados - determinação da composição granulométrica. ABNT, Rio de Janeiro (1987) 3 p.

[11] Associação Brasileira de Normas Técnicas, NBR 7251 - Agregados - determinação da massa unitária. ABNT, Rio de Janeiro (1982) 3 p.

[12] Associação Brasileira de Normas Técnicas, NBR 9776 - Agregados - determinação da massa específica de agregados miúdos por meio do frasco de Chapman. ABNT, Rio de Janeiro (1986) 3 p.

[13] B. D Cullity, Elements of X-Ray Diffraction, $2^{\text {nd }}$ Ed., Addison-Wesley Publishing Co., London, England 
(1956) 511 p.

[14] Associação Brasileira de Normas Técnicas, NBR 5739 - Concreto - ensaio de compressão de corpos de prova cilíndricos. ABNT, Rio de Janeiro (1994) 4 p.
[15] Associação Brasileira de Normas Técnicas, NBR 7211 - Agregados para concreto. ABNT, Rio de Janeiro (1987) 5 p.

(Rec. 09/05/2005, Rev. 27/10/2005, Ac. 23/03/2006) 